\title{
Dairy, calcium, vitamin D and ovarian cancer risk in African-American women
}

\begin{abstract}
Bo Qin ${ }^{*}, 1$, Patricia G Moorman ${ }^{2}$, Anthony J Alberg ${ }^{3}$, Jill S Barnholtz-Sloan ${ }^{4}$, Melissa Bondy ${ }^{5}$, Michele L Cote ${ }^{6}$, Ellen Funkhouser ${ }^{7}$, Edward S Peters $^{8}$, Ann G Schwartz ${ }^{6}$, Paul Terry ${ }^{9}$, Joellen M Schildkraut ${ }^{10}$ and Elisa $V$ Bandera ${ }^{1}$

${ }^{1}$ Population Science, Rutgers Cancer Institute of New Jersey, New Brunswick, NJ 08903, USA; ${ }^{2}$ Department of Community and Family Medicine, Duke Cancer Institute, Durham, NC 27705, USA; ${ }^{3}$ Hollings Cancer Center and Department of Public Health Sciences, Medical University of South Carolina, Charleston, SC 29425, USA; ${ }^{4}$ Case Comprehensive Cancer Center, Case Western Reserve University School of Medicine, Cleveland, OH 44106, USA; ${ }^{5}$ Cancer Prevention and Population Sciences Program, Baylor College of Medicine, Houston, TX 77030, USA; ${ }^{6}$ Department of Oncology and the Karmanos Cancer Institute, Population Studies and Disparities Research Program, Wayne State University School of Medicine, Detroit, MI 48201, USA; 7 Division of Preventive Medicine, University of Alabama at Birmingham, Birmingham, AL 35205, USA; ${ }^{8}$ Epidemiology Program, Louisiana State University Health Sciences Center School of Public Health, New Orleans, LA 70112, USA; ${ }^{9}$ Departments of Public Health and Surgery, University of Tennessee-Knoxville, Knoxville, TN 37996, USA and ${ }^{10}$ Department of Public Health Sciences, University of Virginia, Charlottesville, VA 22908, USA
\end{abstract}

Background: No previous study has evaluated the associations of dairy products, lactose, calcium and vitamin D with the risk of ovarian cancer in African-American women, who are known to have high mortality from the disease, as well as to be at risk for calcium and vitamin D deficiency.

Methods: We evaluated these associations among 490 ovarian cancer cases and 656 age- and site-matched controls of AfricanAmerican descent recruited into the African American Cancer Epidemiology Study, a population-based case-control study in 11 geographical areas in the US. Multivariable logistic regression models were used to estimate odds ratios (ORs) and $95 \%$ confidence intervals (Cls).

Results: An increased ovarian cancer risk was observed for whole milk consumption and lactose intake (highest quartile vs lowest: $\mathrm{OR}=1.97,95 \% \mathrm{Cl}: 1.25-3.10 ; P$-trend: 0.008). Calcium intake was associated with a decreased risk of ovarian cancer (OR $=0.51,95$ Cl\%: 0.30-0.86; P-trend: 0.009), but vitamin D intake was not. Longer sun exposure in summer months was found to predict a lower risk $(\mathrm{OR}=0.71,95 \% \mathrm{Cl}: 0.51-0.99 ; P$-trend: 0.049).

Conclusions: Our findings suggest that a high-calcium, low-lactose diet, and sun exposure in summer months may reduce the risk of ovarian cancer in African-American women.

Ovarian cancer is the fifth leading cause of cancer death among women in the US, of which nearly $90 \%$ are epithelial ovarian carcinomas (Berek et al, 2010). Because currently there is no reliable screening available for ovarian cancer and early-stage ovarian cancer often has no symptoms, most cases are diagnosed at an advanced stage, with a poor prognosis (Goff et al, 2000). Therefore, a better understanding of the aetiology and prevention is especially important for ovarian cancer. Although 5-year survival improved in Whites from 35\% in 1975-1977 to 46\% in 2005-2011, survival actually worsened in African Americans (AAs) during

*Correspondence: Dr B Qin; E-mail: bonnie.qin@rutgers.edu

Received 16 May 2016; revised 8 August 2016; accepted 16 August 2016; published online 15 September 2016

(c) 2016 Cancer Research UK. All rights reserved 0007-0920/16 
this period (rates went from $42 \%$ to $38 \%$; Howlader et al, 2015). The widening gap suggests a critical need for identifying a modifiable risk factors in AA women, an understudied population.

The positive correlation between per capita milk consumption, lactase persistence (the ability to digest lactose), and ovarian cancer incidence (Cramer, 1989a) has led to the hypothesis that the lactose component of dairy - a disaccharide of galactose and glucose, may increase the risk of ovarian cancer through galactose's direct toxicity on oocytes (Cramer et al, 1989b; Liu et al, 2000). Although some studies found positive associations between dairy foods or lactose intake with the risk of ovarian cancer (Kushi et al, 1999; Fairfield et al, 2004; Larsson et al, 2004), others found null (Pan et al, 2004; Webb et al, 1998; Merritt et al, 2013) or inverse association (Goodman et al, 2002; Salazar-Martinez et al, 2002). These study populations were primarily of European ancestry, although no study has published among AAs. The inconsistencies might be attributed to other anti-tumorigenic nutrients in dairy foods, especially calcium and vitamin D. There is enticing evidence that vitamin $\mathrm{D}$ regulates multiple cancer risk and prognosisrelevant pathways, including tumorigenic pathways in ovarian carcinoma (Fleet et al, 2012). Co-administration of calcium was found to enhance the benefits of vitamin D on multiple health outcomes (Feldman et al, 2014). Calcium intake may also independently predict the lower risk of ovarian cancer as suggested by some observational studies (Bidoli et al, 2001; Goodman et al, 2002; Koralek et al, 2006; Merritt et al, 2013), albeit rather inconsistently (Tzonou et al, 1993; Kushi et al, 1999; Genkinger et al, 2006; Chang et al, 2007). It is possible that the opposing associations of calcium or vitamin D and lactose may explain the inconsistent findings between the dairy products and ovarian cancer risk in the current literature.

In addition to food and supplemental intakes, vitamin D in humans can also be produced through skin synthesis upon sun exposure. However, darker colour of the skin reduces the penetration of UVB, resulting in a subsequent less cutaneous synthesis of vitamin D (Webb, 2006). This, together with the tendency of AAs to consume less vitamin D and calcium from dietary sources, due to a higher prevalence of lactose intolerance (Suchy et al, 2010), and supplemental intake (Calvo et al, 2005; Kant et al, 2007) place AA women at risk for vitamin $\mathrm{D}$ deficiency. To our knowledge, this is the first study evaluating intakes of dairy foods, lactose, calcium, and vitamin D exposure (diet and sunlight) and the risk of ovarian cancer among AA women.

\section{MATERIALS AND METHODS}

Design and participants. This study was conducted among AA descent recruited into the African American Cancer Epidemiology Study (AACES), an ongoing population-based casecontrol study of ovarian cancer in AA women in 11 sites in the US (South: Tennessee, North Carolina, South Carolina, Georgia, Alabama, Louisiana, Texas; North: Michigan, Illinois, Ohio, New Jersey) (Schildkraut et al, 2014). Cases were identified by rapid case ascertainment utilising state cancer registries, SEER registries or hospitals' gynaecologic oncology departments. Eligible cases include all self-identified AA women aged between 20 and 79 years, with newly diagnosed, histologically confirmed invasive epithelial ovarian cancer. Controls who self-identified as AAs were selected using random digit dialling and were frequency matched to cases by 5 -year-age groups and state of residence. Women who had a previous history of ovarian cancer or a bilateral oophorectomy were ineligible controls. Among those who could be contacted, $66.5 \%$ of potential cases and $72 \%$ of potential controls agreed to participate in the main telephone interview
(Schildkraut et al, 2014). The study was approved by the Institutional Review Boards at all study sites.

Data were collected by a computer-assisted telephone interview, which included detailed questions on demographic information, personal and family history of cancer, reproductive history, medication use, lifestyle characteristics, and other factors of particular relevance to AA women, such as pigmentation, perceived discrimination, and cultural beliefs. Daily hours spent outdoors in daylight were asked separately on weekdays or weekends, and in summer or the rest of the year.

The present study included 574 cases and 733 controls, who completed the baseline questionnaire via telephone interview by Jan 2016. Although a short version of the questionnaire was offered for those who were not willing to complete the full version $(5.3 \%)$, they were not included in this study since sun exposure, pigmentation and some important covariates for this analysis (e.g., physical activity) were not asked. After excluding 78 cases and 68 controls who did not complete the food frequency questionnaire (FFQ) for dietary assessment, one case and three controls who reported an extreme energy intake (greater than twice the interquartile range of log energy intake), and five cases and six controls with covariates missing, a total of 490 cases and 656 controls remained for the analysis.

Dietary assessment. Dietary information was assessed via a selfadministered Block 2005 FFQ, which included questions on frequency and portion size for 110 food and beverages consumed over the year preceding diagnosis for cases or the reference date for controls (Qin et al, 2016). Dairy intakes were calculated based on the MyPyramid Equivalents Database 2.0 (Bowman et al, 2008). One cup of milk or yogurt ( 8 fluid oz. or $237 \mathrm{ml}$ ) was counted as one milk cup equivalent, that is, one serving in our study. One serving of cheese was between 1 and 2 ounces of natural cheese or processed cheese depending on its calcium content. Milkbased desserts such as ice cream were also considered as dairy products with equivalent servings based on their milk ingredients.

Nutrient intakes were derived by Block Dietary Data Systems based on the USDA Food and Nutrient Database for Dietary Studies 1.0. Supplemental intake of calcium or vitamin D, including multivitamin sources was also collected. Total intake of calcium or vitamin D includes that from both dietary and supplemental sources. Validation studies of the Block FFQ have been described elsewhere (Mares-Perlman et al, 1993; Boucher et al, 2006). The reliability of total calcium or vitamin D intake between the first and second FFQs ( 2 month apart) were 0.80 and 0.76 , respectively. The correlations between estimates from FFQ and two 24 -h recalls were 0.71 and 0.54 for calcium and vitamin D, respectively.

Statistical analysis. We compared the distributions of characteristics between cases and controls using $\chi^{2}$-test or $t$-test as appropriate. We also compared the correlations between intakes of vitamin D, calcium, and lactose using Spearman's rank correlations.

We used unconditional logistic regression models adjusting for the matching factors to estimate odds ratios (ORs) and 95\% confidence intervals (CIs) of ovarian cancer by levels of dairy foods, nutrients (calcium, vitamin D, and lactose), and sun exposure. For total dairy, milk, cheese, total calcium or vitamin $\mathrm{D}$, dietary calcium or vitamin $\mathrm{D}$, lactose, and daylight hours spent outdoors in a year or in summer months, they were categorised into quartiles based on the distributions of controls. For yogurt, milk subtypes (whole milk, skim/low-fat milk), supplemental calcium or vitamin $D$, which had $>25 \%$ non-consumers, they were categorised into three groups, that is, non-consumers, below or above the median of consumption based on controls' distributions. The median value of each category was treated as a continuous variable to test for linear trends. 
The first model adjusted for age, geographic region, and total energy intake. Geographic region was grouped by UV index ( $>5$ and $\leqslant 5$, i.e., South and North states) (NASA Earthdata, 2016). The second model further adjusted for a priori confounders or risk factors for ovarian cancer, including education (high school or less, some post-high school training, and college or graduate degree), parity $(0,1-2,>2)$, oral contraceptive use (never, $<60$ $\mathrm{mo}, \geqslant 60 \mathrm{mo}$ ), menopause status (pre- and post menopause), tubal ligation (no and yes), first-degree family history of breast/ovarian cancer (no and yes), body mass index (BMI, calculated from selfreported weight and height 1 year before), recreational physical activity $(0,<150 \mathrm{~min}$ per week, $\geqslant 150 \mathrm{~min}$ per week 1 year before), skin pigmentation (lighter, average, and darker), daylight hours spent outdoors in summer months (h per week) in models for dietary exposures, and additional covariates for corresponding models: models with dairy were controlled for supplemental calcium and were mutually adjusted for other types of dairy foods when applicable; models with nutrient intakes were adjusted for other sugar intakes (excluding lactose) and were mutually adjusted for each other; models with sun exposure were adjusted for total vitamin D intake from dietary and supplemental sources. Other covariates as listed in Table 1 (e.g., alcohol consumption, talc use, and occupational activity) were considered, but were not adjusted since none changed the effect estimates by $>10 \%$.

We tested for statistical interaction of total dairy, calcium, vitamin $\mathrm{D}$, lactose, daylight hours spent outdoors (in a year or in summer months) between each other (except for dairy), and with skin pigmentation, $\mathrm{BMI}$, menopausal status, and oral contraceptive use via likelihood ratio test. We also conducted analyses by the two histological subtypes contributing the largest number of cases (serous and endometrioid) and tested for heterogeneity. As the stratum sizes would be too small for interaction or histological subtype analyses, we evaluated the dietary exposure as a continuous variable, where 1 unit equals to the interquartile difference of controls' dietary intake. All statistical analyses were performed using Stata (version 14.1; StataCorp LP, College Station, TX, USA).

\section{RESULTS}

Compared with controls, cases were older and less likely to reside in North (Table 1). We found the distributions of ovarian cancer risk factors were in the expected directions. Cases were less likely to have children, to have used oral contraceptives or to have had a tubal ligation, and were more likely to have a family history of breast or ovarian cancer.

The mean (s.d.) intake of dairy products were 6.9 (6.7) and 6.4 (5.8) servings per week among cases and controls, respectively (data not shown). As shown in Table 2, there was a suggestion of a positive association between total dairy or milk intake with ovarian cancer risk, though risk estimates were not statistically significant. In the analyses of milk subtypes, whole milk was significantly associated with a higher risk of ovarian cancer $(\mathrm{OR}=1.85$ comparing $>2.3$ serving per week $v s$ non-consumers, $95 \%$ CI: 1.05-3.27; $P$-trend: 0.02 ), whereas skim/low-fat milk was not. No association was found for cheese or yogurt. Results remained essentially unchanged when adjusting for saturated fat (data not shown).

In the multivariable- and mutually adjusted model, we found calcium intake was consistently associated with a decreased risk of ovarian cancer, with a similar OR for calcium from food, supplement or total (from food plus supplement sources) comparing the highest to the lowest intake category (Table 3). For example, the highest quartile (Q4) of total calcium intake was associated with a $49 \%$ decreased OR (95\% CI: $0.30-0.86$, $P$-trend $=0.009)$. Although calcium intake was highly correlated with vitamin $\mathrm{D}$ intake $(r=0.64, P<0.001$; Supplementary Table 1$)$, we found no association between total or dietary vitamin D with ovarian cancer risk. For supplemental vitamin D intake, we only observed a significant inverse association when comparing the intermediate category (i.e., $\leqslant 371.4 \mathrm{IU}$ per day) $v$ s non-consumers. Lactose intake was found to increase ovarian cancer risk, with an OR of 1.97 comparing Q4 vs Q1 (95\% CI: 1.25-3.10; P-trend: $0.008)$.

In Table 4, the ORs for daylight hours spent outdoors in a year were in the inverse direction, but not statistically significant. The inverse association between outdoor hours in summer months and ovarian cancer risk comparing Q4 vs Q1 was statistical significant $(\mathrm{OR}=0.71 ; 95 \% \mathrm{CI}$ : 0.51-0.99; P-trend: 0.049).

We did not find significant interaction between any two nutrients - total calcium, total vitamin $\mathrm{D}$, and lactose; or between these nutrients and total dairy with sun exposure hours (in a year or in summer months), skin pigmentation, BMI, menopausal status, and oral contraceptive use. In the analyses by serous and endometrioid histologic subtypes (Supplementary Table 2), we observed similar magnitude of associations with continuous scale of total dairy, nutrients, or sun exposure across tumour subtypes. No significant heterogeneity was found.

\section{DISCUSSION}

In this population-based ovarian cancer study of AA women, the positive association between the total dairy intake and ovarian cancer risk seemed to be attributable to the consumption of whole milk. Calcium intake was significantly associated with a reduced risk of ovarian cancer, whereas lactose intake was associated with an increased risk. Sun exposure during the summer was found to decrease the risk of ovarian cancer, but total or dietary vitamin D intake was not.

Our finding of increased risk with whole milk consumption is consistent with a meta-analysis of case-control and cohort studies, analysed either combined or separately by study design (Larsson et al, 2006). However, a pooled analysis of cohort studies found no association with whole milk intake (Genkinger et al, 2006). Their null findings for low-fat milk, cheese, and yogurt were similar to our observations. The previous meta-analysis or pooled analysis did not examine the stratified results among AA women, probably due to a limited statistical power as most study populations were primarily of European ancestry. Our results by milk type were not altered after adjusting for saturated fat intake. Our exploratory analysis showed that dairy fat tended to associate with an increased ovarian cancer risk, but the association was attenuated and became insignificant after adjusting for lactose intake (OR Q4 vs Q1 = 1.48; 95\% CI: 0.88-2.47), which is similar to a previous finding (Bertone et al, 2002). Our results generally support the hypothesis that highlactose dairy foods may raise the risk of ovarian cancer. Both whole milk and low-fat/skim milk, contain on average $12 \mathrm{~g}$ per serving of lactose, much higher than cheese and yogurt (e.g., one serving cheddar cheese contains $0.05 \mathrm{~g}$ lactose and $0.04 \mathrm{~g}$ galactose), although one serving of these dairy products all contain $\sim 300 \mathrm{mg}$ of calcium (Bowman et al, 2008; US Department of Agriculture ARS, Nutrient Data Laboratory, 2015). It is possible that the influence of lactose and potentially fat content in whole milk outweighs the benefits of rich calcium, leading to an increased risk of ovarian cancer risk.

Lactose metabolite, galactose, was found to invariably induce ovarian toxicity in rodent models (Liu et al, 2000). Excessive galactose and galactose metabolites, Gal-1-P and galactitol, may interfere with gonadotrophin signalling and ovarian apoptosis, contributing to the galactose-induced ovarian toxicity (Holschneider and Berek, 2000). Meanwhile, a higher incidence of ovarian failure was observed in patients with galactosemia, due 
Table 1. Selected characteristics of African-American women in AACES ${ }^{a}$

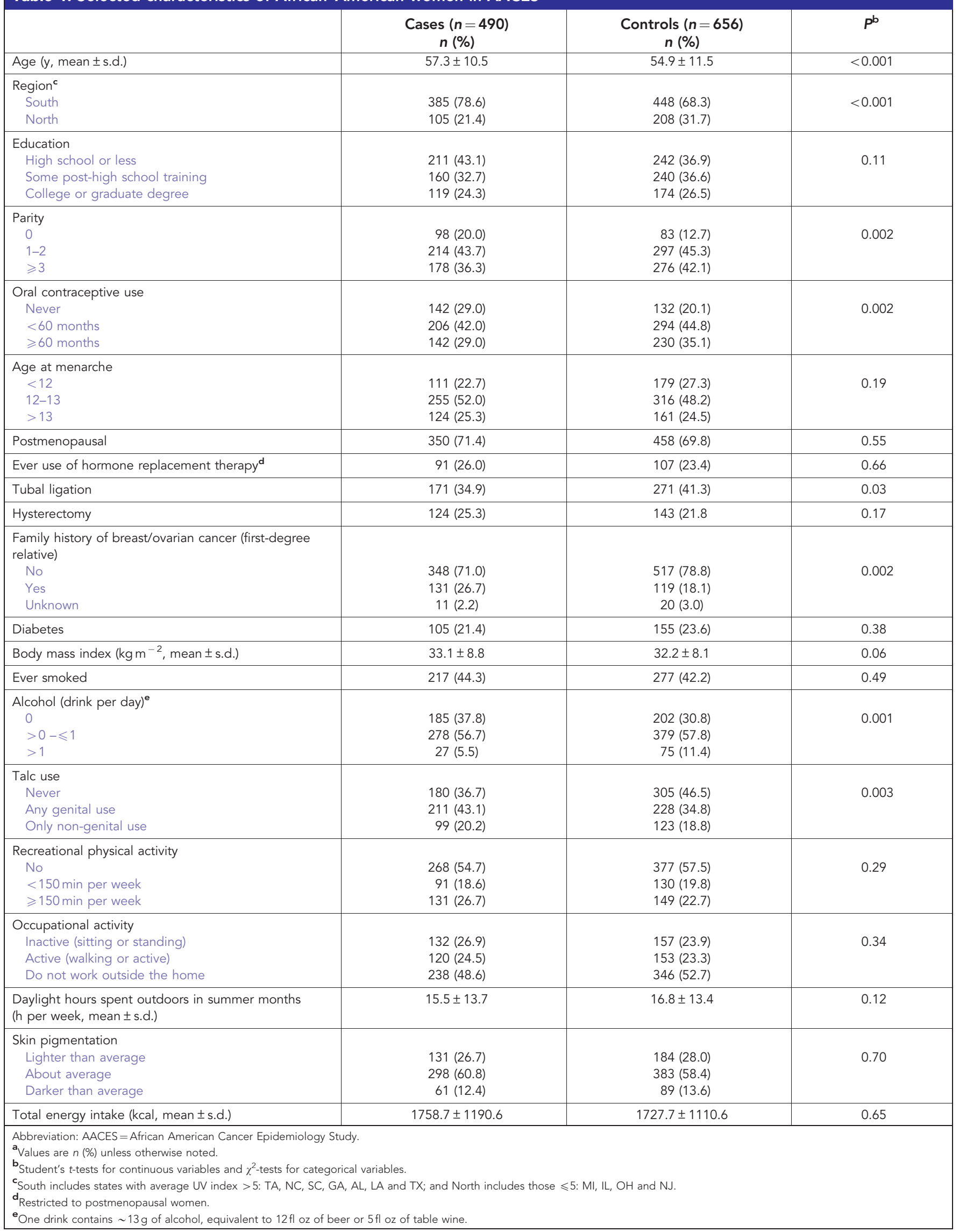


Table 2. Association between dairy products and ovarian cancer risk in AACES ${ }^{a}$

\begin{tabular}{|c|c|c|c|c|c|c|c|c|}
\hline & \multicolumn{2}{|c|}{ Cases $(n=490)$} & \multicolumn{2}{|c|}{ Controls $(n=656)$} & \multicolumn{2}{|c|}{ Model $1^{b}$} & \multicolumn{2}{|c|}{ Model $2^{c}$} \\
\hline & $n$ & $\%$ & $n$ & $\%$ & OR & $95 \% \mathrm{Cl}$ & OR & $95 \% \mathrm{Cl}$ \\
\hline \multicolumn{9}{|c|}{ Total dairy (serving per week) } \\
\hline \multirow{5}{*}{$\begin{array}{l}\text { Q1 }(\leqslant 2.6) \\
\text { Q2 }(2.7-4.7) \\
\text { Q3 }(4.8-8.3) \\
\text { Q4 }(\geqslant 8.4) \\
\text { P for trend }\end{array}$} & \multirow{5}{*}{$\begin{array}{l}103 \\
144 \\
118 \\
125\end{array}$} & \multirow{5}{*}{$\begin{array}{l}21.0 \\
29.4 \\
24.1 \\
25.5\end{array}$} & \multirow{5}{*}{$\begin{array}{l}168 \\
167 \\
157 \\
164\end{array}$} & \multirow{5}{*}{$\begin{array}{l}25.6 \\
25.5 \\
23.9 \\
25.0\end{array}$} & \multirow{4}{*}{$\begin{array}{l}1.00 \\
1.41 \\
1.22 \\
1.37\end{array}$} & \multirow{4}{*}{$\begin{array}{c}\text { Ref } \\
1.01,1.98 \\
0.85,1.75 \\
0.90,2.08\end{array}$} & 1.00 & \multirow{4}{*}{$\begin{array}{c}\text { Ref } \\
1.04,2.11 \\
0.91,1.92 \\
0.95,2.28\end{array}$} \\
\hline & & & & & & & 1.48 & \\
\hline & & & & & & & 1.32 & \\
\hline & & & & & & & 1.48 & \\
\hline & & & & & \multicolumn{2}{|c|}{0.36} & \multicolumn{2}{|c|}{0.25} \\
\hline \multicolumn{9}{|c|}{ Milk (serving per week) } \\
\hline \multirow{5}{*}{$\begin{array}{l}\text { Q1 }(\leqslant 0.8) \\
\text { Q2 }(0.9-1.7) \\
\text { Q3 }(1.8-4.1) \\
\text { Q4 }(\geqslant 4.2) \\
P \text { for trend }\end{array}$} & \multirow{5}{*}{$\begin{array}{l}103 \\
121 \\
139 \\
127\end{array}$} & \multirow{5}{*}{$\begin{array}{l}21.0 \\
24.7 \\
28.4 \\
25.9\end{array}$} & \multirow{5}{*}{$\begin{array}{l}161 \\
161 \\
173 \\
161\end{array}$} & \multirow{5}{*}{$\begin{array}{l}24.5 \\
24.5 \\
26.4 \\
24.5\end{array}$} & \multirow{5}{*}{$\begin{array}{l}1.00 \\
1.15 \\
1.22 \\
1.26 \\
\end{array}$} & \multirow{5}{*}{$\begin{array}{c}\text { Ref } \\
0.81,1.64 \\
0.86,1.72 \\
0.85,1.88 \\
\end{array}$} & 1.00 & \multirow{5}{*}{$\begin{array}{c}\text { Ref } \\
0.83,1.74 \\
0.83,1.75 \\
0.87,2.05\end{array}$} \\
\hline & & & & & & & 1.20 & \\
\hline & & & & & & & 1.20 & \\
\hline & & & & & & & 1.34 & \\
\hline & & & & & & & & \\
\hline \multicolumn{9}{|c|}{ Whole milk (serving per week) } \\
\hline \multirow{4}{*}{$\begin{array}{l}\text { Non-consumer } \\
\leqslant 2.3 \\
>2.3 \\
P \text { for trend }\end{array}$} & \multirow{4}{*}{$\begin{array}{c}356 \\
56 \\
78\end{array}$} & 72.7 & 511 & 77.9 & 1.00 & Ref & 1.00 & Ref \\
\hline & & 11.4 & 73 & 11.1 & 1.13 & $0.77,1.66$ & 1.20 & $0.68,2.12$ \\
\hline & & 15.9 & 72 & 11.0 & 1.61 & $1.10,2.35$ & 1.85 & $1.05,3.27$ \\
\hline & & & & & & & & \\
\hline Skim/low-fat mi & er w & & & & & & & \\
\hline Non-consumer & 178 & 36.3 & 209 & 31.9 & 1.00 & Ref & 1.00 & Ref \\
\hline$\leqslant 2.0$ & 157 & 32.0 & 229 & 34.9 & 0.82 & $0.61,1.11$ & 1.11 & $0.69,1.77$ \\
\hline$>2.0$ & 155 & 31.6 & 218 & 33.2 & 0.84 & $0.63,1.12$ & 1.06 & $0.66,1.70$ \\
\hline$P$ for trend & & & & & & & & \\
\hline Cheese (serving & & & & & & & & \\
\hline Q1 $(\leqslant 0.9)$ & 116 & 23.7 & 159 & 24.2 & 1.00 & Ref & 1.00 & Ref \\
\hline Q2 (1.0-1.7) & 119 & 24.3 & 158 & 24.1 & 1.08 & $0.76,1.52$ & 1.10 & $0.76,1.58$ \\
\hline O3 (1.8-3.1) & 129 & 26.3 & 174 & 26.5 & 1.09 & $0.77,1.54$ & 1.18 & $0.82,1.71$ \\
\hline $\mathrm{Q} 4(\geqslant 3.2)$ & 126 & 25.7 & 165 & 25.2 & 1.19 & $0.79,1.79$ & 1.25 & $0.81,1.92$ \\
\hline$P$ for trend & & & & & & & & \\
\hline Yogurt (serving & & & & & & & & \\
\hline Non-consumer & 213 & 43.5 & 263 & 40.1 & 1.00 & Ref & 1.00 & Ref \\
\hline$<0.5$ & 144 & 29.4 & 218 & 33.2 & 0.82 & $0.62,1.09$ & 0.84 & $0.62,1.13$ \\
\hline$\geqslant 0.5$ & 133 & 27.1 & 175 & 26.6 & 0.95 & $0.70,1.27$ & 0.93 & $0.67,1.28$ \\
\hline$P$ for trend & & & & & & & & \\
\hline $\begin{array}{l}\text { Abbreviations: AACES } \\
\mathbf{a}_{\text {Exposures were cate }} \\
\text { median of consumpti } \\
\mathbf{b}_{\text {Model } 1 \text { adjusted fo }} \\
{ }^{c_{M}} \text { Model } 2 \text { further adju } \\
\text { months, pigmentation }\end{array}$ & $\begin{array}{l}\text { can Ca } \\
\text { rtiles b } \\
\text { trols' d } \\
\text { d total } \\
\text { on, pari }\end{array}$ & $\begin{array}{l}\text { e. } \\
\text { maceptive } \\
\text { mass in }\end{array}$ & $\begin{array}{l}\text { onfiden } \\
\text { ols. For } \\
\text { pausal }\end{array}$ & $\begin{array}{l}\mathrm{OR}=\mathrm{od} \\
\text { with }>25 \\
\text { I ligation } \\
\text { ke, and }\end{array}$ & $\begin{array}{l}\text { sumers, } \\
\text { tory of } b \\
\text { djusted } f\end{array}$ & $\begin{array}{l}\text { re categorised } \\
\text { varian cancer, } \\
\text { types of dairy }\end{array}$ & ours sp & oors in summe \\
\hline
\end{tabular}

to a deficient activity of galactose-1-phosphate uridyl transferase (GALT) (Kaufman et al, 1981), which, in turn, is caused by GALT gene mutations. Among several polymorphisms, S135L is almost exclusively found in AAs (Tyfield et al, 1999). It is possible that a higher lactose consumption, which is beyond the GALT activity, may introduce a greater risk of ovarian cancer.

Consistent with this hypothesis, and the findings from a pooling study and a meta-analysis of prospective studies (Genkinger et al, 2006; Larsson et al, 2006), we found lactose intake increased ovarian cancer risk in AAs. Two cohort studies found this association was stronger for serous tumours (Fairfield et al, 2004; Larsson et al, 2004), whereas most case-control studies did not observe this positive relation among all cases or across tumour subtypes (Webb et al, 1998; Pan et al, 2004; Merritt et al, 2013). Compared with the previous studies that were mainly conducted in European or EuropeanAmerican women, our study of AA women had, on average, lower intakes of milk and lactose. AAs are more likely to have lactose intolerance than European Americans (Suchy et al, 2010), which may, in part, explain the reduced intake of milk and lactose in this population. For example, in the National Health and Nutrition
Examination Survey AA adults had much lower intake of total dairy or milk (mean \pm s.d.: $0.48 \pm 0.06$ serving per day) compared with other races ( $0.93 \pm 0.07$ serving per day; Fulgoni et al, 2007), which is consistent with our findings. Because of the lower intakes in the reference group, we may be more likely to detect the relation with milk and lactose than other case-control studies.

The other two abundant nutrients from dairy foods are calcium and vitamin $\mathrm{D}$, which represent the largest contributor of total calcium and vitamin D intake of the US population (37\% and $49 \%$, respectively) regardless of supplemental intake (Barainca et al, 2014; Hoy and Goldman, 2014). We identified a consistent inverse association with total, dietary and supplemental intakes of calcium, independent of a wide array of non-dietary and dietary factors. For vitamin D intake, we only observed a suggestive decreased risk with that from supplemental sources. Although we have mutually adjusted for each other, the high correlations between calcium and vitamin $\mathrm{D}$ made it challenging to evaluate their independent associations with ovarian cancer, particularly between supplemental calcium and vitamin $\mathrm{D}$, which often go together in available supplements. Our findings with calcium were supported by some 
Table 3. Association between intakes of calcium, vitamin D and lactose with ovarian cancer risk in AACES

\begin{tabular}{|c|c|c|c|c|c|c|c|c|}
\hline & \multicolumn{2}{|c|}{ Cases $(n=490)$} & \multicolumn{2}{|c|}{ Controls $(n=656)$} & \multicolumn{2}{|c|}{ Model $1^{b}$} & \multicolumn{2}{|c|}{ Model $2^{c}$} \\
\hline & $n$ & $\%$ & $n$ & $\%$ & OR & $95 \% \mathrm{Cl}$ & OR & $95 \% \mathrm{Cl}$ \\
\hline \multicolumn{9}{|c|}{ Total calcium (mg per day) } \\
\hline \multirow{5}{*}{$\begin{array}{l}\text { Q1 }(\leqslant 478.6) \\
\text { Q2 (478.7-784.1) } \\
\text { Q3 }(784.2-1233.6) \\
\text { Q4 ( } \geqslant 1233.7) \\
P \text { for trend }\end{array}$} & \multirow{5}{*}{$\begin{array}{l}298 \\
306 \\
272 \\
270\end{array}$} & \multirow{5}{*}{$\begin{array}{l}26.0 \\
26.7 \\
23.7 \\
23.6\end{array}$} & \multirow{5}{*}{$\begin{array}{l}164 \\
164 \\
164 \\
164\end{array}$} & \multirow{5}{*}{$\begin{array}{l}25.0 \\
25.0 \\
25.0 \\
25.0\end{array}$} & 1.00 & Ref & 1.00 & Ref \\
\hline & & & & & 1.00 & $0.72,1.39$ & 0.89 & $0.61,1.31$ \\
\hline & & & & & 0.70 & $0.48,1.00$ & 0.62 & $0.39,0.96$ \\
\hline & & & & & 0.63 & $0.42,0.94$ & 0.51 & $0.30,0.86$ \\
\hline & & & & & \multicolumn{2}{|c|}{0.012} & \multicolumn{2}{|c|}{0.009} \\
\hline \multicolumn{9}{|c|}{ Dietary calcium (mg per day) } \\
\hline \multirow{5}{*}{$\begin{array}{l}\text { Q1 }(\leqslant 362.4) \\
\text { Q2 }(362.5-546.8) \\
\text { Q3 }(546.9-819.5) \\
\text { Q4 ( } \geqslant 819.6) \\
P \text { for trend }\end{array}$} & \multirow{5}{*}{$\begin{array}{l}123 \\
128 \\
126 \\
113\end{array}$} & \multirow{5}{*}{$\begin{array}{l}25.1 \\
26.1 \\
25.7 \\
23.1\end{array}$} & \multirow{5}{*}{$\begin{array}{l}164 \\
164 \\
164 \\
164\end{array}$} & \multirow{5}{*}{$\begin{array}{l}25.0 \\
25.0 \\
25.0 \\
25.0\end{array}$} & 1.00 & \multirow{5}{*}{$\begin{array}{c}\text { Ref } \\
0.70,1.37 \\
0.65,1.35 \\
0.48,1.23\end{array}$} & 1.00 & \multirow{5}{*}{$\begin{array}{c}\text { Ref } \\
0.54,1.17 \\
0.47,1.20 \\
0.28,0.98\end{array}$} \\
\hline & & & & & 0.98 & & 0.79 & \\
\hline & & & & & 0.94 & & 0.75 & \\
\hline & & & & & 0.77 & & 0.52 & \\
\hline & & & & & & & & \\
\hline \multicolumn{9}{|c|}{ Supplemental calcium (mg per day) } \\
\hline \multirow{4}{*}{$\begin{array}{l}\text { Non-consumer } \\
\leqslant 240.0 \\
>240.0 \\
P \text { for trend }\end{array}$} & \multirow{4}{*}{$\begin{array}{l}231 \\
143 \\
116\end{array}$} & & 240 & 36.6 & 1.00 & Ref & 1.00 & Ref \\
\hline & & 29.2 & 214 & 32.6 & 0.69 & $0.52,0.91$ & 0.62 & $0.41,0.92$ \\
\hline & & 23.7 & 202 & 30.8 & 0.57 & $0.43,0.77$ & 0.52 & $0.35,0.79$ \\
\hline & & & & & & & & \\
\hline Total vitamin D & per day) & & & & & & & \\
\hline Q1 $(\leqslant 130.8)$ & 313 & 27.3 & 164 & 25.0 & 1.00 & Ref & 1.00 & Ref \\
\hline Q2 (130.9-292.8) & 262 & 22.9 & 164 & 25.0 & 0.63 & $0.45,0.89$ & 0.72 & $0.49,1.04$ \\
\hline Q3 (292.9-523.9) & 282 & 24.6 & 164 & 25.0 & 0.77 & $0.55,1.07$ & 0.89 & $0.60,1.32$ \\
\hline $\mathrm{Q} 4(\geqslant 524.0)$ & 289 & 25.2 & 164 & 25.0 & 0.75 & $0.54,1.05$ & 1.00 & $0.65,1.54$ \\
\hline$P$ for trend & & & & & & & & \\
\hline Dietary vitamin & IU per day & & & & & & & \\
\hline Q1 $(\leqslant 48.5)$ & 124 & 25.3 & 164 & 25.0 & 1.00 & $\operatorname{Ref}$ & 1.00 & Ref \\
\hline Q2 (48.6-80.8) & 114 & 23.3 & 164 & 25.0 & 0.90 & $0.64,1.27$ & 0.84 & $0.57,1.25$ \\
\hline Q3 (80.9-141.1) & 115 & 23.5 & 164 & 25.0 & 0.91 & $0.64,1.30$ & 0.85 & $0.54,1.33$ \\
\hline $\mathrm{O} 4(\geqslant 141.2)$ & 137 & 28.0 & 164 & 25.0 & 1.12 & $0.75,1.66$ & 1.02 & $0.58,1.79$ \\
\hline$P$ for trend & & & & & & & & \\
\hline Supplemental vi & $\operatorname{nin} D(I U p$ & & & & & & & \\
\hline Non-consumer & 200 & 40.8 & 189 & 28.8 & 1.00 & Ref & 1.00 & Ref \\
\hline$\leqslant 371.4$ & 134 & 27.4 & 257 & 39.2 & 0.49 & $0.37,0.66$ & 0.54 & $0.39,0.74$ \\
\hline$>371.4$ & 156 & 31.8 & 210 & 32.0 & 0.67 & $0.50,0.89$ & 0.78 & $0.55,1.12$ \\
\hline & & & & & & & & \\
\hline Lactose (g per d & & & & & & & & \\
\hline Q1 ( $\leqslant 2.3)$ & 104 & 21.22 & 170 & 25.9 & 1.00 & Ref & 1.00 & Ref \\
\hline Q2 (2.4-4.6) & 137 & 27.96 & 164 & 25.0 & 1.41 & $1.00,1.98$ & 1.44 & $1.00,2.08$ \\
\hline Q3 (4.7-8.8) & 108 & 22.04 & 158 & 24.1 & 1.12 & $0.78,1.61$ & 1.19 & $0.79,1.78$ \\
\hline $\mathrm{Q} 4(\geqslant 8.9)$ & 141 & 28.78 & 164 & 25.0 & 1.53 & $1.02,2.29$ & 1.97 & $1.25,3.10$ \\
\hline$P$ for trend & & & & & & & & \\
\hline 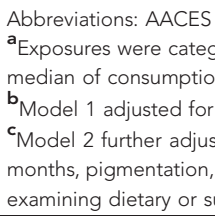 & $\begin{array}{l}\text { frican America } \\
\text { ed into quartil } \\
\text { ased on contrc } \\
\text { e, region, and } \\
\text { for education, } \\
\text { reational physi } \\
\text { lemental intak }\end{array}$ & $\begin{array}{l}\text { idemiolo } \\
\text { the distr } \\
\text { ons. } \\
\text { intake. } \\
\text { contrace } \\
\text { ody mass } \\
\text { (or vitam }\end{array}$ & $\begin{array}{l}=\text { confic } \\
\text { ontrols. } \\
\text { enopau } \\
\text { er sugar }\end{array}$ & $\begin{array}{l}\text { IU, int } \\
\text { with }> \\
\text { al ligati } \\
\text { ig lact }\end{array}$ & $\begin{array}{l}\text { it; OR= } \\
\text { nsumers } \\
\text { story of } \\
\text { rtiles of }\end{array}$ & arian cancer, c & lactose & $\begin{array}{l}\text { w or above the } \\
\text { pors in summe } \\
\text { plicable; When }\end{array}$ \\
\hline
\end{tabular}

cohort and case-control studies (Bidoli et al, 2001; Goodman et al, 2002; Koralek et al, 2006; Merritt et al, 2013), but not all (Tzonou et al, 1993; Kushi et al, 1999; Genkinger et al, 2006; Chang et al, 2007). A recent case-control study suggested that the association was stronger for mucinous ovarian cancer (Merritt et al, 2013). Considering that mucinous tumours of the ovary usually originate from the colorectum, and exhibit similar mutational patterns as mucinous carcinomas of the colorectum (Kelemen and Kobel, 2011), the protective effect of calcium intake on colorectal cancer may also apply to the mucinous type ovarian cancer (Cho et al, 2004). Because of the small number of mucinous cases $(n=25)$, we were not able to restrict analyses to this subtype.
However, our findings were not altered when mucinous cases were excluded.

Calcium may also protect against advanced ovarian cancer, as a mediator of vitamin D-induced apoptosis (Sergeev, 2004). Data from animal models of ovarian cancer showed consistent evidence that calcitriol, the active form of vitamin D, could suppress the growth of ovarian cancer (Zhang et al, 2005). However, evidence from epidemiological studies was rather inconsistent (Cook et al, 2010). Except a few (Salazar-Martinez et al, 2002; Merritt et al, 2013), most studies including ours did not observe a decreased risk with vitamin D intake (Kushi et al, 1999; Genkinger et al, 2006; Koralek et al, 2006; Chang et al, 2007). However, the ecological 
Table 4. Daylight hours spent outdoors and ovarian cancer risk in AACES ${ }^{a}$

\begin{tabular}{|c|c|c|c|c|c|c|c|c|}
\hline & \multicolumn{2}{|c|}{ Cases $(n=490)$} & \multicolumn{2}{|c|}{ Controls $(n=656)$} & \multicolumn{2}{|c|}{ Model $1^{b}$} & \multicolumn{2}{|c|}{ Model $2^{c}$} \\
\hline & n & $\%$ & $n$ & $\%$ & OR & $95 \% \mathrm{Cl}$ & OR & $95 \% \mathrm{Cl}$ \\
\hline \multicolumn{9}{|c|}{ Weekly average of daylight hours spent outdoors in a year (h per week) } \\
\hline Q1 $(\leqslant 5)$ & 146 & 29.8 & 163 & 24.9 & 1.00 & Ref & 1.00 & Ref \\
\hline Q2 (6-10) & 88 & 18.0 & 120 & 18.3 & 0.85 & $0.59,1.22$ & 0.82 & $0.57,1.20$ \\
\hline Q3 (11-16) & 131 & 26.7 & 198 & 30.2 & 0.76 & $0.55,1.04$ & 0.72 & $0.52,1.00$ \\
\hline $\mathrm{Q} 4(\geqslant 17)$ & 125 & 25.5 & 175 & 26.7 & 0.85 & $0.61,1.19$ & 0.84 & $0.59,1.20$ \\
\hline$P$ for trend & & & & & \multicolumn{2}{|c|}{0.43} & \multicolumn{2}{|c|}{0.46} \\
\hline \multicolumn{9}{|c|}{ Weekly average of daylight hours spent outdoors in summer months (h per week) } \\
\hline Q1 $(\leqslant 6)$ & 160 & 32.7 & 178 & 27.1 & 1.00 & Ref & 1.00 & Ref \\
\hline Q2 (7-11) & 135 & 27.6 & 176 & 26.8 & 0.86 & $0.63,1.18$ & 0.86 & $0.62,1.20$ \\
\hline Q3 (12-22) & 76 & 15.5 & 105 & 16.0 & 0.87 & $0.60,1.25$ & 0.91 & $0.62,1.34$ \\
\hline $\mathrm{O} 4(\geqslant 23)$ & 119 & 24.3 & 197 & 30.0 & 0.71 & $0.52,0.98$ & 0.71 & $0.51,0.99$ \\
\hline$P$ for trend & & & & & \multicolumn{2}{|c|}{0.041} & \multicolumn{2}{|c|}{0.049} \\
\hline \multicolumn{9}{|c|}{$\begin{array}{l}\text { Abbreviations: AACES = African American Cancer Epidemiology Study; } \mathrm{Cl}=\text { confidence interval; } \mathrm{OR}=\text { odds ratio. } \\
\mathrm{a}_{\text {Exposures were categorised based on approximate quartiles among controls. }} \\
\mathrm{b}_{\text {Model } 1 \text { adjusted for age, region, and total energy intake. }} \\
{ }^{c} \text { Model } 2 \text { further adjusted for education, parity, oral contraceptive use, menopausal status, tubal ligation, family history of breast/ovarian cancer, pigmentation, recreational physical activity } \\
\text { body mass index, and total vitamin D intake. }\end{array}$} \\
\hline
\end{tabular}

studies that evaluated UVB radiation and ovarian mortality rates invariably found an inverse correlation (Grant, 2012), which supported our finding that sun exposure in summer months predicted a lower risk of ovarian cancer. Vitamin D synthesis was thought to be the most important physiological effect of sun exposure, despite other pathways such as circadian rhythm that have been proposed as well (van der Rhee et al, 2013). Although we were not able to collect serum samples before diagnosis, a metaanalysis or a pooling study of circulating vitamin D concentration found a tentative inverse association among all women (Yin et al, 2011), or an inverse association among women who were overweight or obese (Zheng et al, 2010). Relatively similar findings for vitamin $\mathrm{D}$ status and sun exposure in relation to ovarian cancer may be explained by the observation that the circulating level of vitamin $\mathrm{D}$ is determined primarily by exposure to sunlight (Adams et al, 1982). It is suggested that sun exposure for 5-15 min between 1000 hours and 1500 hours during spring, summer, and fall can help produce an adequate amount of vitamin D for Whites, AAs need 5-10 times longer exposure to synthesise the same amount of vitamin $\mathrm{D}$, as their skin pigment reduce the penetration of UVB (Holick, 2011). However, because the benefits of sun exposure may be offset by increased risk of skin cancer, a combination of moderate sun exposure and sufficient vitamin D intakes from diet and supplements may be a safer solution for an adequate vitamin D status. In our study, $<20 \%$ of AA women achieved the recommended daily vitamin D intake of at least $600 \mathrm{IU}$ (or $800 \mathrm{IU}$ if beyond 70 years; Ross et al, 2011), a threshold mainly based on the evidence in skeletal health. It has been hypothesised, but remains to be explored whether higher daily doses of vitamin $\mathrm{D}$ would be required for anticancer actions than that for bone health (Feldman et al, 2014).

We recognised the limitations of dietary recall in case-control studies. However, the largely unknown relation between intakes of vitamin $\mathrm{D}$, calcium or dairy foods, and ovarian cancer and, as a result, lack of awareness of this link in this population should minimise this problem. To reduce the potential that undetected disease influenced dietary recall, cases were asked to report their diet 1 year before diagnosis that is beyond the median prediagnostic symptom duration (4 months) for invasive cases (Vine et al, 2001). The potential for selection bias is another concern, especially when the participation rates in population-based epidemiologic studies have been declining. However, the distribution of risk factors among cases and controls in our study were in the expected directions compared with other studies among AA women (Moorman et al, 2009), which increased our confidence in the validity of our findings. In addition, residual confounding is possible despite the multivariable and mutually adjusted models. We did not have information on sunscreen use or clothing habits, which could attenuate the negative associations between daylight outdoor hours in the summer and the risk of ovarian cancer. Nevertheless, the prevalence of sun-protection behaviours among AAs is low (e.g., 63\% never used sunscreen; Hall and Rogers, 1998).

A main strength of our study is that we were able to recruit a large sample of AA ovarian cancer cases and controls from various geographic regions, and with diverse socioeconomic and lifestyle characteristics, which imparts our ability to generalise the results to the AA population. Our study adds to the scarce literature on the aetiology of ovarian cancer in AA women.

Considering that there is no effective screening tool for ovarian cancer and the poorer survival of AA patients, prevention is critical, particularly through lifestyle or dietary modifications, which are less costly and risky than medical treatments. Our findings suggest that sun exposure in summer months and a highcalcium, low-lactose diet may benefit ovarian cancer prevention in AA women.

\section{ACKNOWLEDGEMENTS}

We acknowledge the AACES interviewers, Christine Bard, LaTonda Briggs, Whitney Franz (North Carolina), and Robin Gold (Detroit). We also acknowledge the individuals responsible for facilitating case ascertainment across the 10 sites including: Jennifer Burczyk-Brown (Alabama); Rana Bayakly, Vicki Bennett, and Judy Andrews (Georgia); the Louisiana Tumour Registry; Lisa Paddock and Manisha Narang (New Jersey); Diana Slone, Steven Waggoner, Anne Heugel, Nancy Fusco, Kelly Ferguson, Peter Rose, Deb Strater, Taryn Ferber, Donna White, Lynn Borzi, Eric Jenison, Nairmeen Haller, Debbie Thomas, Vivian von Gruenigen, Michele McCarroll, Joyce Neading, John Geisler, Stephanie Smiddy, David Cohn, Michele Vaughan, Luis Vaccarello, Elayna Freese, James Pavelka, Pam Plummer, William Nahhas, Ellen Cato, John Moroney, Mark Wysong, Tonia Combs, Marci Bowling, Brandon Fletcher, Yingli Wolinsky (Ohio); Susan Bolick, Donna Acosta, Catherine Flanagan (South Carolina); Martin Whiteside (Tennessee) and Georgina Armstrong and the Texas Registry, Cancer Epidemiology and Surveillance Branch, Department of 
State Health Services. The current study was supported by the New Jersey Commission on Cancer Research. The AACES study was funded by NCI (R01CA142081). Additional support was provided by Metropolitan Detroit Cancer Surveillance System (MDCSS) with federal funds from the National Cancer Institute, National Institute of Health, Deptartment of Health and Human Services, under contract no. HHSN261201000028C and the Epidemiology Research Core, supported in part by NCI Center Grant (P30CA22453) to the Karmanos Cancer Institute, Wayne State University School of Medicine and NCI Center Grant (P30CA072720) to the Rutgers Cancer Institute of New Jersey. The New Jersey State Cancer Registry, Cancer Epidemiology Services, New Jersey Department of Health is funded by the Surveillance, Epidemiology and End Results (SEER) Program of the National Cancer Institute under contract HHSN261201300021I, the National Program of Cancer Registries (NPCR), Centers for Disease Control and Prevention under grant 5U58DP003931-02, as well as the State of New Jersey and the Rutgers Cancer Institute of New Jersey.

\section{CONFLICT OF INTEREST}

The authors declare no conflict of interest.

\section{REFERENCES}

Adams JS, Clemens TL, Parrish JA, Holick MF (1982) Vitamin-D Synthesis and metabolism after ultraviolet irradiation of normal and vitamin-Ddeficient subjects. N Engl J Med 306(12): 722-725.

Barainca P, Rhodes D, Clemens J, Moshfegh A (2014) Vitamin D: intake of Americans from diet and supplements (632.10). FASEB J 28(Suppl 1).

Berek JS, Friedlander ML, Robert C, Bast J (2010) Ovarian Cancer. In Holland-Frei Cancer Medicine, Kufe DW, Iii EF, Holland JF et al. (eds) 8th edn, pp 1344-1375. People's Medical Publishing House-USA: Shelton, CT, USA.

Bertone ER, Rosner BA, Hunter DJ, Stampfer MJ, Speizer FE, Colditz GA, Willett WC, Hankinson SE (2002) Dietary fat intake and ovarian cancer in a cohort of US women. Am J Epidemiol 156(1): 22-31.

Bidoli E, Vecchia CL, Talamini R, Negri E, Parpinel M, Conti E, Montella M, Carbone A, Franceschi S (2001) Micronutrients and ovarian cancer: a case-control study in Italy. Ann Oncol 12(11): 1589-1593.

Boucher B, Cotterchio M, Kreiger N, Nadalin V, Block T, Block G (2006) Validity and reliability of the Block98 food-frequency questionnaire in a sample of Canadian women. Public Health Nutr 9(01): 84-93.

Bowman SA, Friday JE, Moshfegh AJ (2008) MyPyramid Equivalents Database, 2.0 for USDA survey foods, 2003-2004: documentation and user guide. Food Surveys Research Group Beltsville Human Nutrition Research Center, Agricultural Research Service, US Department of Agriculture: Beltsville, MD, USA.

Calvo MS, Whiting SJ, Barton CN (2005) Vitamin D intake: a global perspective of current status. J Nutr 135(2): 310-316.

Chang ET, Lee VS, Canchola AJ, Clarke CA, Purdie DM, Reynolds P, Anton-Culver H, Bernstein L, Deapen D, Peel D, Pinder R, Ross RK, Stram DO, West DW, Wright W, Ziogas A, Horn-Ross PL (2007) Diet and risk of ovarian cancer in the California Teachers Study cohort. Am J Epidemiol 165(7): 802-813.

Cho E, Smith-Warner SA, Spiegelman D, Beeson WL, van den Brandt PA, Colditz GA, Folsom AR, Fraser GE, Freudenheim JL, Giovannucci E, Goldbohm RA, Graham S, Miller AB, Pietinen P, Potter JD, Rohan TE, Terry P, Toniolo P, Virtanen MJ, Willett WC, Wolk A, Wu K, Yaun SS, Zeleniuch-Jacquotte A, Hunter DJ (2004) Dairy foods, calcium, and colorectal cancer: a pooled analysis of 10 cohort studies. J Natl Cancer Inst 96(13): 1015-1022.

Cook LS, Neilson HK, Lorenzetti DL, Lee RC (2010) A systematic literature review of vitamin D and ovarian cancer. Am J Obstet Gynecol 203(170): e1-e8.

Cramer DW (1989a) Lactase persistence and milk consumption as determinants of ovarian cancer risk. Am J Epidemiol 130(5): 904-910.
Cramer DW, Willett WC, Bell DA, Ng WG, Harlow BL, Welch WR, Scully RE, Knapp RC (1989b) Galactose consumption and metabolism in relation to the risk of ovarian cancer. Lancet 2(8654): 66-71.

Fairfield KM, Hunter DJ, Colditz GA, Fuchs CS, Cramer DW, Speizer FE, Willett WC, Hankinson SE (2004) A prospective study of dietary lactose and ovarian cancer. Int J Cancer 110(2): 271-277.

Feldman D, Krishnan AV, Swami S, Giovannucci E, Feldman BJ (2014) The role of vitamin $\mathrm{D}$ in reducing cancer risk and progression. Nat Rev Cancer 14(5): 342-357.

Fleet JC, Desmet M, Johnson R, Li Y (2012) Vitamin D and cancer: a review of molecular mechanisms. Biochem J 441(1): 61-76.

Fulgoni 3rd V, Nicholls J, Reed A, Buckley R, Kafer K, Huth P, DiRienzo D, Miller GD (2007) Dairy consumption and related nutrient intake in African-American adults and children in the United States: continuing survey of food intakes by individuals 1994-1996, 1998, and the National Health And Nutrition Examination Survey 1999-2000. J Am Diet Assoc 107(2): 256-264.

Genkinger JM, Hunter DJ, Spiegelman D, Anderson KE, Arslan A, Beeson WL, Buring JE, Fraser GE, Freudenheim JL, Goldbohm RA, Hankinson SE, Jacobs Jr. DR, Koushik A, Lacey Jr. JV, Larsson SC, Leitzmann M, McCullough ML, Miller AB, Rodriguez C, Rohan TE, Schouten LJ, Shore R, Smit E, Wolk A, Zhang SM, Smith-Warner SA (2006) Dairy products and ovarian cancer: a pooled analysis of 12 cohort studies. Cancer Epidemiol Biomarkers Prev 15(2): 364-372.

Goff BA, Mandel L, Muntz HG, Melancon CH (2000) Ovarian carcinoma diagnosis. Cancer 89(10): 2068-2075.

Goodman MT, Wu AH, Tung KH, McDuffie K, Kolonel LN, Nomura AM, Terada K, Wilkens LR, Murphy S, Hankin JH (2002) Association of dairy products, lactose, and calcium with the risk of ovarian cancer. Am J Epidemiol 156(2): 148-157.

Grant WB (2012) Ecological studies of the UVB-vitamin D-cancer hypothesis. Anticancer Res 32(1): 223-236.

Hall H, Rogers J (1998) Sun protection behaviors among African Americans. Ethn Dis 9(1): 126-131.

Holick MF (2011) Vitamin D: a d-lightful solution for health. J Investig Med 59(6): 872-880.

Holschneider CH, Berek JS (2000) Ovarian cancer: epidemiology, biology, and prognostic factors. Semin Surg Oncol 19(1): 3-10.

Howlader N, Noone AM, Krapcho M, Garshell J, Miller D, Altekruse SF, Kosary CL, Yu M, Ruhl J, Tatalovich Z, Mariotto A, Lewis DR, Chen HS, Feuer EJ, Cronin KA (2015) SEER Cancer Statistics Review, 1975-2012. National Cancer Institute Bethesda: MD, USA.

Hoy MK, Goldman JD (2014) Calcium intake of the US population, What We Eat in America, NHANES 2009-2010. Food Surveys Research Group: Dietary Data Brief No. 13.

Kant AK, Graubard BI, Kumanyika SK (2007) Trends in black-white differentials in dietary intakes of U.S. adults, 1971-2002. Am J Prev Med 32(4): 264-272.

Kaufman FR, Kogut MD, Donnell GN, Goebelsmann U, March C, Koch R (1981) Hypergonadotropic hypogonadism in female patients with galactosemia. N Engl J Med 304(17): 994-998.

Kelemen LE, Kobel M (2011) Mucinous carcinomas of the ovary and colorectum: different organ, same dilemma. Lancet Oncol 12(11): 1071-1080.

Koralek DO, Bertone-Johnson ER, Leitzmann MF, Sturgeon SR, Lacey Jr. JV, Schairer C, Schatzkin A (2006) Relationship between calcium, lactose, vitamin D, and dairy products and ovarian cancer. Nutr Cancer 56(1): 22-30.

Kushi LH, Mink PJ, Folsom AR, Anderson KE, Zheng W, Lazovich D, Sellers TA (1999) Prospective study of diet and ovarian cancer. Am J Epidemiol 149(1): 21-31.

Larsson SC, Bergkvist L, Wolk A (2004) Milk and lactose intakes and ovarian cancer risk in the Swedish Mammography Cohort. Am J Clin Nutr 80(5): 1353-1357.

Larsson SC, Orsini N, Wolk A (2006) Milk, milk products and lactose intake and ovarian cancer risk: a meta-analysis of epidemiological studies. Int $J$ Cancer 118(2): 431-441.

Liu G, Hale GE, Hughes CL (2000) Galactose metabolism and ovarian toxicity. Reprod Toxicol 14(5): 377-384.

Mares-Perlman JA, Klein B, Klein R, Ritter LL, Fisher MR, Freudenheim JL (1993) A diet history questionnaire ranks nutrient intakes in middle-aged and older men and women similarly to multiple food records. J Nutr 123(3): 489-501. 
Merritt MA, Cramer DW, Vitonis AF, Titus LJ, Terry KL (2013) Dairy foods and nutrients in relation to risk of ovarian cancer and major histological subtypes. Int J Cancer 132(5): 1114-1124.

Moorman PG, Palmieri RT, Akushevich L, Berchuck A, Schildkraut JM (2009) Ovarian cancer risk factors in African-American and white women. Am J Epidemiol 170(5): 598-606.

NASA Earthdata (2016) Available at http://giovanni.sci.gsfc.nasa.gov/ giovanni/ (accessed on 21 February 2016).

Pan SY, Ugnat AM, Mao Y, Wen SW, Johnson KC (2004) A case-control study of diet and the risk of ovarian cancer. Cancer Epidemiol Biomarkers Prev 13(9): 1521-1527.

Qin B, Moorman PG, Alberg AJ, Barnholtz-Sloan JS, Bondy M, Cote ML, Funkhouser E, Peters ES, Schwartz AG, Terry P, Schildkraut JM, Bandera EV (2016) Dietary carbohydrate intake, glycaemic load, glycaemic index and ovarian cancer risk in African-American women. Br J Nutr 115(4): 694-702.

Ross AC, Manson JE, Abrams SA, Aloia JF, Brannon PM, Clinton SK, Durazo-Arvizu RA, Gallagher JC, Gallo RL, Jones G, Kovacs CS, Mayne ST, Rosen CJ, Shapses SA (2011) The 2011 report on dietary reference intakes for calcium and vitamin D from the Institute of Medicine: what clinicians need to know. J Clin Endocrinol Metab 96(1): 53-58.

Salazar-Martinez E, Lazcano-Ponce EC, Gonzalez Lira-Lira G, Escudero-De los Rios P, Hernandez-Avila M (2002) Nutritional determinants of epithelial ovarian cancer risk: a case-control study in Mexico. Oncology 63(2): 151-157.

Schildkraut JM, Alberg AJ, Bandera EV, Barnholtz-Sloan J, Bondy M, Cote ML, Funkhouser E, Peters E, Schwartz AG, Terry P (2014) A multicenter population-based case-control study of ovarian cancer in AfricanAmerican women: the African American Cancer Epidemiology Study (AACES). BMC Cancer 14(1): 688.

Sergeev IN (2004) Calcium as a mediator of 1,25-dihydroxyvitamin D3-induced apoptosis. J Steroid Biochem Mol Biol 89-90: 419-425.

Suchy FJ, Brannon PM, Carpenter TO, Fernandez JR, Gilsanz V, Gould JB, Hall K, Hui SL, Lupton J, Mennella J, Miller NJ, Osganian SK, Sellmeyer DE, Wolf MA (2010) National Institutes of Health Consensus Development Conference: lactose intolerance and health. Ann Int Med 152(12): 792-796.

Tyfield L, Reichardt J, Fridovich-Keil J, Croke DT, Elsas 2nd LJ, Strobl W, Kozak L, Coskun T, Novelli G, Okano Y, Zekanowski C, Shin Y, Boleda MD (1999) Classical galactosemia and mutations at the galactose-1-phosphate uridyl transferase (GALT) gene. Hum Mutat 13(6): 417-430.
Tzonou A, Hsieh CC, Polychronopoulou A, Kaprinis G, Toupadaki N, Trichopoulou A, Karakatsani A, Trichopoulos D (1993) Diet and ovarian cancer: a case-control study in Greece. Int J Cancer 55(3): 411-414.

US Department of Agriculture ARS, Nutrient Data Laboratory (2015) USDA National Nutrient Database for Standard Reference, Release 28. Version Current: September 2015. Available at https://www.ars.usda.gov/ northeast-area/beltsville-md/beltsville-human-nutrition-research-center/ nutrient-data-laboratory/docs/usda-national-nutrient-database-forstandard-reference/ (accessed on 04 January 2016).

van der Rhee H, Coebergh JW, de Vries E (2013) Is prevention of cancer by sun exposure more than just the effect of vitamin D? A systematic review of epidemiological studies. Eur J Cancer 49(6): 1422-1436.

Vine MF, Ness RB, Calingaert B, Schildkraut JM, Berchuck A (2001) Types and duration of symptoms prior to diagnosis of invasive or borderline ovarian tumor. Gynecol Oncol 83(3): 466-471.

Webb AR (2006) Who, what, where and when-influences on cutaneous vitamin D synthesis. Prog Biophys Mol Biol 92(1): 17-25.

Webb PM, Bain CJ, Purdie DM, Harvey PW, Green A (1998) Milk consumption, galactose metabolism and ovarian cancer (Australia). Cancer Causes Control 9(6): 637-644.

Yin L, Grandi N, Raum E, Haug U, Arndt V, Brenner H (2011) Meta-analysis: Circulating vitamin D and ovarian cancer risk. Gynecol Oncol 121(2): 369-375.

Zhang X, Jiang F, Li P, Li C, Ma Q, Nicosia SV, Bai W (2005) Growth Suppression of Ovarian Cancer Xenografts in Nude Mice by Vitamin D Analogue EB1089. Clin Cancer Res 11(1): 323-328.

publication-type="journal" $>$ Zheng W, Danforth KN, Tworoger SS, Goodman MT, Arslan AA, Patel AV, McCullough ML, Weinstein SJ, Kolonel LN, Purdue MP, Shu XO, Snyder K, Steplowski E, Visvanathan K, Yu K, Zeleniuch-Jacquotte A, Gao YT, Hankinson SE, Harvey C, Hayes RB, Henderson BE, Horst RL, Helzlsouer KJ (2010) Circulating 25-hydroxyvitamin D and risk of epithelial ovarian cancer: Cohort Consortium Vitamin D Pooling Project of Rarer Cancers. Am J Epidemiol 172(1): 70-80.

This work is published under the standard license to publish agreement. After 12 months the work will become freely available and the license terms will switch to a Creative Commons AttributionNonCommercial-Share Alike 4.0 Unported License.

Supplementary Information accompanies this paper on British Journal of Cancer website (http://www.nature.com/bjc) 